Research Article

\title{
High genetic diversity among and within bitter manioc varieties cultivated in different soil types in Central Amazonia
}

\author{
Alessandro Alves-Pereira ${ }^{1,2}$, Nivaldo Peroni ${ }^{3}$, Marcelo Mattos Cavallari ${ }^{4}$, Maristerra R. Lemes ${ }^{5,6}$, Maria \\ Imaculada Zucchi ${ }^{7}$ and Charles R. Clement ${ }^{2,5}$ \\ ${ }^{1}$ Departamento de Genética, Escola Superior de Agricultura "Luiz de Queiróz”, Universidade de São \\ Paulo, Piracicaba, SP, Brazil. \\ ${ }^{2}$ Laboratório de Evolução Aplicada, Universidade Federal do Amazonas, Manaus, AM, Brazil. \\ ${ }^{3}$ Universidade Federal de Santa Catarina, Departamento de Ecologia e Zoologia, Florianópolis, SC, Brazil. \\ ${ }^{4}$ Empresa Brasileira de Pesquisa Agropecuária, EMBRAPA COCAIS, São Luis, MA, Brazil. \\ ${ }^{5}$ Instituto Nacional de Pesquisas da Amazônia, Manaus, AM, Brazil. \\ ${ }^{6}$ Laboratório de Genética e Biologia Reprodutiva de Plantas, Instituto Nacional de Pesquisas da Amazônia, \\ Manaus, AM, Brazil. \\ ${ }^{7}$ Agência Paulista de Tecnologia dos Agronegócios, Pólo Regional Centro-Sul, Piracicaba, SP, Brazil.
}

\begin{abstract}
Although manioc is well adapted to nutrient-poor Oxisols of Amazonia, ethnobotanical observations show that bitter manioc is also frequently cultivated in the highly fertile soils of the floodplains and Amazonian dark earths (ADE) along the middle Madeira River. Because different sets of varieties are grown in each soil type, and there are agronomic similarities between ADE and floodplain varieties, it was hypothesized that varieties grown in ADE and floodplain were more closely related to each other than either is to varieties grown in Oxisols. We tested this hypothesis evaluating the intra-varietal genetic diversity and the genetic relationships among manioc varieties commonly cultivated in Oxisols, ADE and floodplain soils. Genetic results did not agree with ethnobotanical expectation, since the relationships between varieties were variable and most individuals of varieties with the same vernacular name, but grown in ADE and floodplain, were distinct. Although the same vernacular name could not always be associated with genetic similarities, there is still a great amount of variation among the varieties. Many ecological and genetic processes may explain the high genetic diversity and differentiation found for bitter manioc varieties, but all contribute to the maintenance and amplification of genetic diversity within the manioc in Central Amazonia.
\end{abstract}

Keywords: Manihot esculenta, microsatellites, Amazonian dark earths, floodplain, Oxisols.

Received: February 28, 2016; Accepted: November 16, 2016.

\section{Introduction}

Manioc (Manihot esculenta Crantz ssp. esculenta) was domesticated in southwestern Amazonia at least 7,000 years ago (Allem, 1994; Olsen and Schaal, 1999) and today is cultivated in all tropical countries (Lebot, 2009). It is grown for its tuberous starchy roots, which are the primary source of carbohydrates for more than 800 million people (Lebot, 2009). Cultivated manioc is classified into two major groups of varieties. The "sweet" varieties have low amounts of cyanogenic glycosides $(<100 \mathrm{ppm}$ fresh weight), while "bitter" varieties have high amounts of these toxic substances (>100 ppm fresh weight) (McKey et al.,

Send correspondence to Charles Roland Clement. Instituto Nacional de Pesquisas da Amazônia, Av. André Araújo, 2936, Petrópolis, CEP 69067-375, Manaus, AM, Brazil. e-mail: cclement@inpa.gov.br. 2010a). The discrimination of these two groups is recognized by traditional farmers (Rival and McKey, 2008), and supported by molecular markers (Mühlen et al., 2000; Peroni et al., 2007).

There is strong selection for manioc varieties with high toxicity, especially in Central Amazonia where the majority of varieties are bitter (McKey and Beckerman, 1993). Bitter manioc is most frequently grown on the nutrient-poor Oxisols of non-flooded upland plateaus (Fraser and Clement, 2008). However, manioc is also cultivated in the highly fertile Fluvent Entisols found in the floodplains of Amazonian white-water rivers (Gutjahr, 2000). Bitter manioc is also a widespread crop in the highly fertile Amazonian dark earths (ADE) used by communities of smallholder farmers along the middle Madeira River (Fraser, 2010). ADE are anthropogenic soils, located on upland plateaus, associated with Amerindian settlements from the 
pre-Columbian period (Glaser and Birk, 2012), and are as fertile as the floodplain soils. Despite the importance of manioc cultivation on high-fertility soils, all previously published research on manioc genetic diversity in Amazonia was undertaken in environments of low soil fertility.

In Amazonia, manioc is generally cultivated in lowinput swidden-fallow systems of traditional farmers (Emperaire, 2005), where secondary vegetation is cleared and burnt, and the swiddens are used for cultivation and then fallowed. Secondary vegetation is left to grow for a variable period before the area is again used for cultivation (Elias et al., 2000). Although the cultivation of manioc is based exclusively on clonal propagation, sexual reproduction may be a very common spontaneous event as volunteer seedlings sprout after the burn and grow at the same time as plants that were vegetatively propagated (Pujol et al., 2007). Farmers may let the seedlings grow and by harvesting time they may decide to propagate some of these plants vegetatively (Rival and McKey, 2008). If so, farmers may either incorporate them into an existing variety or assign a new varietal name (Rival and McKey, 2008). The process of incorporation of seedlings is essential to maintain genetic diversity within the crop (Pujol et al., 2007; Duputié et al., 2009) and results in polyclonal varieties.

Based on ethnobotanical observation, Fraser (2010) suggested that traditional farmers along the middle Madeira River manage distinct sets of varieties according to their suitability for the different environments of cultivation, which are characterized principally by soil type and by the occurrence, or not, of annual flooding (ADE and Oxisols on the uplands $v s$. Entisols in the floodplain). Soil type is classified by traditional farmers as "weak" (soils that are more intensively cultivated, with short cropping cycles and shorter fallowing periods, such as ADE soils) and "strong" (soils that are more extensively cultivated, with short cycles of cultivation and longer fallowing periods, such as Oxisols). These authors observed that local varieties of bitter manioc are termed "weak" (low starch, fast maturing) or "strong" (high starch, slow maturing) according to their suitability for cultivation in "weak" or "strong" soils, respectively. In addition, due to the seasonality of flood events, bitter manioc varieties cultivated in the floodplain mature quickly (like "weak" varieties). For these reasons, the authors hypothesized that the "weak" varieties have origins traceable to the floodplain soils, and thus one would expect that the varieties grown in ADE are genetically related to the varieties grown in the floodplain. A few interviews with farmers also supported this hypothesis (Fraser, 2010).

Fraser (2010) also observed that the classification of the soils may change according to their intensity of use, and farmers may select a new set of varieties more suitable for the soil type (Fraser and Clement, 2008). This variation in the perception of the suitability of varieties for different soil types may cause, for example, farmers to grow low starch fast maturing "weak" varieties on "strong" soils (Oxisols) that are more intensively cultivated. Therefore, gene flow among varieties adapted to different soil types is probable through sexual reproduction and incorporation of seedlings.

Despite the existence of distinct sets of varieties preferentially grown in each soil type, farmers along the middle Madeira River may still cultivate varieties with the same vernacular name in different environments than the most suitable one (Fraser et al., 2012). Therefore, the cultivation system of this region is an ideal scenario to evaluate the genetic similarities and relationships among bitter manioc varieties in light of these ethnobotanical expectations. The objective of this study was to test a hypothesis raised by ethnobotanical observations that manioc varieties from $\mathrm{ADE}$ and the floodplain are genetically more closely related to each other, based on the assessment of genetic diversity using molecular tools. We evaluated the genetic diversity and structure among 14 of the most common varieties grown in different soil types in smallholder farming communities along the middle Madeira River region using ten microsatellite loci. The patterns of genetic diversity are discussed with the aim of integrating the accumulated knowledge on genetic diversity and ethnobotany of the crop.

\section{Material and Methods}

\section{Sampling sites and permission}

The manioc varieties analyzed in this study are amongst the most frequently grown in different soil types found in Manicoré $\left(5^{\circ} 18^{\prime} \mathrm{S} ; 61^{\circ} 18^{\prime} \mathrm{W}\right)$, an essentially agricultural municipality located in Amazonas state, Brazil, along the middle Madeira River (Fraser, 2010). The manioc varieties were sampled in the riverside non-indigenous communities of Água Azul, Barreira do Capanã, Barro Alto, Pau Queimado and Verdum (Figure 1), which are composed of smallholder farmers who grow manioc in traditional swidden-fallow systems in upland ADE and Oxisols, as well as in floodplain soils. At each community, the project goals were explained to the farmers, in order to obtain prior informed consent. This work met Resolution 21 requirements for basic research and was exempted from authorization by Brazil's Council for Genetic Patrimony (CGEN in the Brazilian acronym), which was consulted before field work. Our study was authorized by the Instituto Nacional de Pesquisas da Amazônia's Committee for Research Ethics (Permit number 235/09) and our collecting was registered in the System for Authorization and Information on Biodiversity, coordinated by the Chico Mendes Institute for Biodiversity of the Ministry of the Environment (number of register: 10020-5).

A total of 14 manioc varieties (with nine different vernacular names) were sampled: four in ADE, five in the floodplain and five in Oxisols (Table 1). Leaves were collected, dried in silica gel, and stored at $-20{ }^{\circ} \mathrm{C}$ until DNA extraction. 


\section{DNA extraction and microsatellite genotyping}

Genomic DNA was extracted from $50 \mathrm{mg}$ of powdered leaf tissue using the CTAB $2 \%$ method described by
Doyle and Doyle (1987) with a minor modification (the reagent 2-mercaptethanol was not used). DNA was quantified by comparison with known concentrations of standard

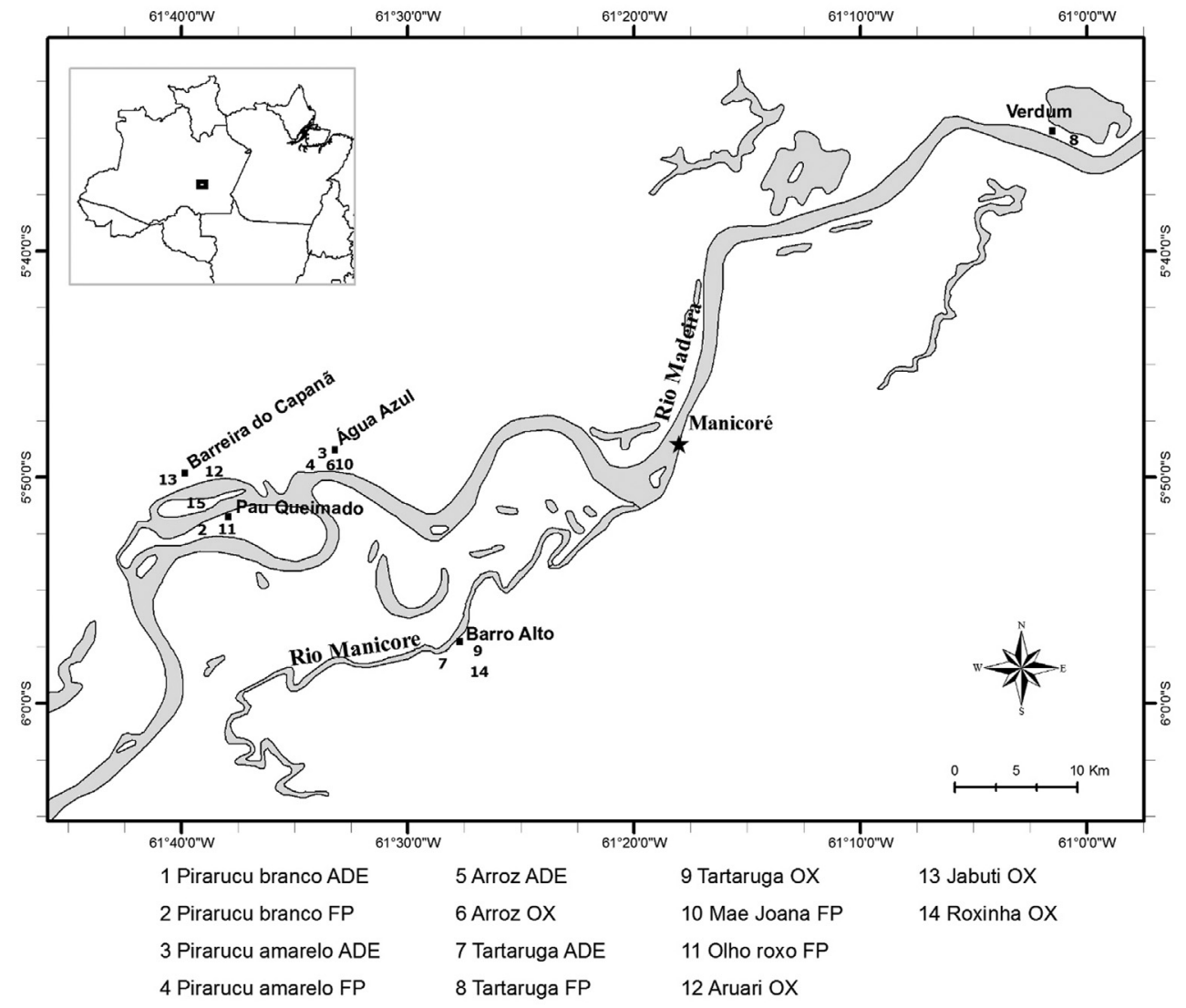

Figure 1 - Map showing the communities of smallholder farmers in the municipality of Manicoré, along the middle Madeira River, Amazonas, Brazil, where manioc varieties were sampled. The numbers correspond to the varieties' names and the soil types in which they were grown. Soil types are coded as ADE (Amazonian dark earths), FP (floodplain) and OX (Oxisols).

Table 1 - Manioc varieties sampled in different soils of different communities of smallholder farmers in the municipality of Manicoré, along the middle Madeira River, Amazonas, Brazil. $\mathrm{N}$ = number of individuals sampled.

\begin{tabular}{|c|c|c|c|c|}
\hline Vernacular name & Soil & Variety Acronym & $\mathrm{N}$ & Community \\
\hline \multirow[t]{2}{*}{ Pirarucu Branco } & $\mathrm{ADE}$ & PB ADE & 20 & Barreira do Capanã \\
\hline & Floodplain & PB FP & 20 & Pau Queimado \\
\hline \multirow[t]{2}{*}{ Pirarucu Amarelo } & $\mathrm{ADE}$ & PA ADE & 30 & Água Azul \\
\hline & Floodplain & PA FP & 30 & Água Azul \\
\hline \multirow[t]{2}{*}{ Arroz } & $\mathrm{ADE}$ & AR ADE & 20 & Barreira do Capanã \\
\hline & Oxisol & AR OX & 30 & Água Azul \\
\hline \multirow[t]{3}{*}{ Tartaruga } & $\mathrm{ADE}$ & TA ADE & 30 & Barro Alto \\
\hline & Floodplain & TA FP & 30 & Verdum \\
\hline & Oxisol & TA OX & 30 & Barro Alto \\
\hline Mãe Joana & Floodplain & MJ FP & 30 & Água Azul \\
\hline Olho Roxo & Floodplain & OR FP & 30 & Pau Queimado \\
\hline Aruari & Oxisol & AU OX & 30 & Barreira do Capanã \\
\hline Jabuti & Oxisol & JA OX & 30 & Barreira do Capanã \\
\hline Roxinha & Oxisol & RO OX & 30 & Barro Alto \\
\hline
\end{tabular}


DNA (lambda DNA, Fermentas, Carlsbad, USA) in electrophoresis agarose gels $(0.9 \% \mathrm{w} / \mathrm{v})$ stained with GelRed (Biotium Inc., San Francisco, USA).

Seven microsatellite markers (GA21, GA126, GA131, GA134, GA136, GA140, GAGG5) developed by Chavarriaga-Aguirre et al. (1998), and three (SSRY13, SSRY89, SSRY164) developed by Mba et al. (2001) were used. The microsatellite markers developed by Chavarriaga-Aguirre et al. (1998) were isolated from the MCol22 accession of the manioc germplasm collection at the International Centre for Tropical Agriculture, Cali, Colombia (CIAT), with the aim of the mapping and characterizing the genetic variability of CIAT's core collection. The microsatellites described by Mba et al. (2001) were isolated from the improved manioc variety TMS 30572, developed at the International Institute of Tropical Agriculture, Ibadan, Nigeria, (IITA), as part of an effort to generate molecular markers to saturate a genetic map of manioc. The utility of these microsatellite markers for the assessment of genetic diversity of manioc has been demonstrated in previous studies (Bradbury et al., 2013; Mühlen et al., 2013). PCR assays were carried out in a final volume of $10 \mu \mathrm{L}$ with $20 \mathrm{ng}$ of genomic DNA, $1 \mathrm{X}$ buffer $\left(\mathrm{Mg}^{2+}\right.$ free), $2.5 \mathrm{ng}$ of BSA, $2.5 \mathrm{mM}$ of $\mathrm{MgCl}_{2}, 250 \mu \mathrm{M}$ of each dNTP, 2.5 pmols of each forward and reverse primer, and $1 \mathrm{U}$ Taq DNA polymerase (Fermentas). Amplifications were carried out in a Verirti thermocycler (Applied Biosystems, Inc, Foster City, USA) as follows: an initial denaturation step of $94{ }^{\circ} \mathrm{C}$ for $2 \mathrm{~min}$ followed by 30 cycles at $94{ }^{\circ} \mathrm{C}$ for $1 \mathrm{~min}$; $56{ }^{\circ} \mathrm{C}$ for $1 \mathrm{~min} ; 72^{\circ} \mathrm{C}$ for $2 \mathrm{~min}$, and a final step of extension at $72{ }^{\circ} \mathrm{C}$ for $25 \mathrm{~min}$. The quality of the PCR products was checked by electrophoresis in agarose gels $(2 \% \mathrm{w} / \mathrm{v})$ stained with GelRed. Forward sequences of the microsatellite primers were labeled with fluorescence (either FAM, 6-HEX or NED), and genotyping was performed in multiplexed systems in a DNA sequencer ABI3130xl (Applied Biosystems). GeneScanTM -500 $\mathrm{ROX}^{\mathrm{TM}}$ - size standard (Applied Biosystems) was used for allele sizing. Data collection and analysis were performed using GeneMapper v.4.0 (Applied Biosystems). According to the manufacturer, since the size standard is added to each sample, the process of calling alleles is very precise. However, as a standard procedure, in the case of samples that did not present clear patterns for allele calling, genotyping was performed more than once.

\section{Data analysis}

\section{Intra-varietal genetic diversity}

Genetic diversity parameters of total $(A)$ and mean $(\bar{A})$ number of alleles, observed $\left(H_{O}\right)$ and expected $\left(H_{E}\right)$ heterozygosities, number of private alleles $(A p)$ and the inbreeding coefficient $(f)$ were estimated with GenAlEx v.6.5 (Peakall and Smouse, 2012) for each locus and variety, and for the groups of varieties of each soil type. Significance of $f$ was determined with Genetix v.4.03 (Belkhir et al., 2002), based on 10,000 bootstrap replicates. The recognition of identical and distinct multilocus genotypes (MLGs) was performed with GenClone v.2.0 (Arnaud-Haond and Belkhir, 2007) in order to investigate the presence of common MLGs among different varieties. Individuals with missing data were excluded from this analysis.

\section{Genetic structure}

Two methods were used to investigate the genetic structure and relationships among varieties. First we used discriminant analysis of principal components (DAPC, Jombart et al., 2010), a multivariate analysis with no underlying model run with the adegenet R package (Jombart and Ahmed, 2011). Previous to the analysis we used the $K$ means clustering algorithm, also implemented in adegenet, to set $K=11$ as the prior grouping criterion (Figure $\mathrm{S} 1$ ). Based on these 11 clusters we ran DAPC retaining 10 principal components (corresponding to $98.73 \%$ of total variation). To access stability of group membership probabilities generated in DAPC, we used the a-score criterion also implemented in adegenet. We then compared the DAPC individuals' assignments to those obtained with TESS (Chen et al., 2007). TESS implements a Bayesian model based on Hidden Markov Random Field (HMRF), which models spatial dependencies at the cluster membership level of individuals being tested. The program searches for significant geographical discontinuities in allele frequencies determining population structure from individual multilocus genotypes sampled at different geographical locations. The interaction parameter $\psi$ controls the importance given to spatial interactions, and when set to zero the HMRF model assumes a non-informative spatial prior, which corresponds to the no admixture, uncorrelated allele frequencies model implemented in Structure (Pritchard et al., 2000; Durand et al., 2009). TESS was run with the no admixture model, with $\psi=$ zero for a period of 50,000 steps after a burn in period of 10,000 . With these configurations we aimed to perform an analysis similar to what may be performed with Structure, but with the advantage of not having the constraints of the assumptions of Hardy-Weinberg equilibrium and minimization of linkage disequilibrium within clusters. Ten independent runs were performed for each value of the maximal number of clusters $\left(K_{\max }\right)$, with $K_{\max }$ varying from two to 20 . Selection of the $K_{\max }$ that best fit data was performed with the Deviance Information Criterion (DIC, Figure S1) in a way similar to the ad hoc $\Delta K$ criterion used for Structure results (Evanno et al., 2005).

The genetic differentiation among varieties was additionally investigated by estimating pairwise fixation indexes $\left(F_{S T}\right)$ using Arlequin v.3.5 (Excoffier and Lischer, 2010). Significance tests were carried out with 1,000 bootstrap replicates. Because varieties have a great number of individuals with identical MLGs, these estimates were calculated retaining only one individual per MLG found within each variety. Although the results of these analyses may be difficult to discuss in terms of genetic structuring, 
we aimed to evaluate allelic composition differentiation across varieties. To evaluate the distribution of genetic variation among the varieties, analysis of molecular variance (AMOVA) was performed with Arlequin v.3.5 (Excoffier and Lischer, 2010). Statistical significance for the data was assessed based upon 20,000 permutations. Again, this analysis was performed retaining only one individual per MLG found within each variety.

Nei et al. (1983) genetic distances $\left(\mathrm{D}_{\mathrm{A}}\right)$ were estimated among the varieties with MSA v.4.05 (Dieringer and Schlötterer, 2003), and a dendrogram was constructed using the Neighbor-Joining method (Saitou and Nei, 1987) implemented by PHYLIP v.3.6 (Felsenstein, 2005). Significance was estimated with 1,000 bootstrap replicates. The final tree was formatted with FigTree (http://tree.bio.ed.ac.uk/software/figtree/).

\section{Results}

\section{Intra-varietal genetic diversity}

The whole set of individuals $(\mathrm{N}=390)$ presented two to eight alleles per locus and an average of 4.5 alleles over all loci (data not shown). All 14 varieties had higher observed heterozygosities than expected by random mating and the excess of heterozygotes was reflected in negative values of inbreeding (Table 2). Observed heterozygosities were also higher than expected heterozygosities for all soil types; the floodplain varieties had a slightly higher mean observed heterozygosity than did varieties from ADE and Oxisols, which had similar mean values of $H_{O}$. The varieties Tartaruga and Olho Roxo from the floodplain, and Aruari and Jabuti from Oxisols, had private alleles. Most of the private alleles that were found across soil types had frequencies greater than 0.05 (Table S1).

A total of 35 MLGs were detected. Twenty-one of them occurred in only one individual in the whole set of individuals (unique MLGs, Table 2), and were distributed in eight varieties (Figure 2a). The other 14 MLGs were shared by two to 73 individuals (Table S2). High molecular genetic variability was observed among varieties, as shown by the multilocus genotypes (MLGs) detected within each variety (Figure 2a), confirming the polyclonal status of most varieties. Pirarucu Amarelo from the floodplain and Roxinha from Oxisols were the only two varieties with a single MLG in our sample. The other varieties showed at least two different MLGs, and the Oxisol variety Jabuti presented six different MLGs.

\section{Genetic structure among varieties}

The $K$-means clustering method defined 11 clusters from the set of 14 bitter manioc varieties with DAPC (Figure $2 b$ ). Membership coefficients based on individuals' assignments to DAPC clusters were used to plot a Structure-like barplot (Figure 2c), which revealed that varieties were grouped in ten major clusters (one of the DAPC clusters was composed by only one individual of Aruari grown

Table 2 - Genetic diversity parameters estimated for 14 bitter manioc varieties grown in three different soil types in Manicoré, Amazonas, Brazil, and for the set of varieties in each soil type, based on 10 microsatellite loci. Number of individuals $(\mathrm{N})$, mean number of alleles $(\bar{A})$, number of private alleles (Ap), number of multilocus genotypes (MLGs), number of unique multilocus genotypes (uMLGs), observed $\left(H_{O}\right)$ and expected $\left(H_{E}\right)$ heterozygosities and inbreeding coefficients $(f)$. Soil types are coded as ADE (Amazonia dark earths), FP (floodplain) and OX (Oxisols). Significant values of $f^{*}(\mathrm{p}<0.05)$ are indicated.

\begin{tabular}{lcccccccc}
\hline Varieties/Soil types & $\mathrm{N}$ & $\bar{A}$ & $\mathrm{Ap}$ & MLGs & uMLGs & $H_{O}$ & $H_{E}$ & $f$ \\
\hline Pirarucu Branco ADE & 20 & 1.5 & - & 2 & 1 & 0.495 & 0.250 & $-0.981^{*}$ \\
Pirarucu Branco FP & 20 & 1.6 & - & 2 & 1 & 0.505 & 0.255 & $-0.838^{*}$ \\
Pirarucu Amarelo ADE & 30 & 1.7 & - & 2 & - & 0.607 & 0.306 & $-0.862^{*}$ \\
Pirarucu Amarelo FP & 30 & 1.8 & - & 1 & - & 0.607 & 0.307 & $-0.754^{*}$ \\
Arroz ADE & 20 & 2.4 & - & 5 & 3 & 0.495 & 0.460 & -0.076 \\
Arroz OX & 30 & 1.7 & - & 2 & 1 & 0.503 & 0.257 & $-0.752^{*}$ \\
Tartaruga ADE & 30 & 2.2 & - & 2 & - & 0.503 & 0.268 & $-0.530^{*}$ \\
Tartaruga FP & 30 & 2 & 3 & 5 & 3 & 0.707 & 0.361 & $-0.770^{*}$ \\
Tartaruga OX & 30 & 2.4 & - & 4 & 1 & 0.507 & 0.276 & $-0.445^{*}$ \\
Mãe Joana FP & 30 & 2.5 & - & 5 & 3 & 0.593 & 0.363 & $-0.451^{*}$ \\
Olho Roxo FP & 30 & 2 & 2 & 4 & 3 & 0.510 & 0.266 & $-0.695^{*}$ \\
Aruari OX & 30 & 2.4 & 3 & 3 & 2 & 0.583 & 0.329 & $-0.357^{*}$ \\
Jabuti OX & 30 & 2.6 & 1 & 6 & 3 & 0.567 & 0.445 & $-0.157^{*}$ \\
Roxinha OX & 30 & 1.5 & - & 1 & - & 0.500 & 0.250 & $-1.000^{*}$ \\
ADE & 100 & 3.3 & 1 & 9 & 4 & 0.532 & 0.505 & $-0.053^{*}$ \\
Floodplain & 140 & 3.6 & 6 & 17 & 10 & 0.590 & 0.510 & $-0.156^{*}$ \\
Oxisols & 150 & 3.6 & 5 & 15 & 7 & 0.531 & 0.526 & -0.009 \\
\hline
\end{tabular}



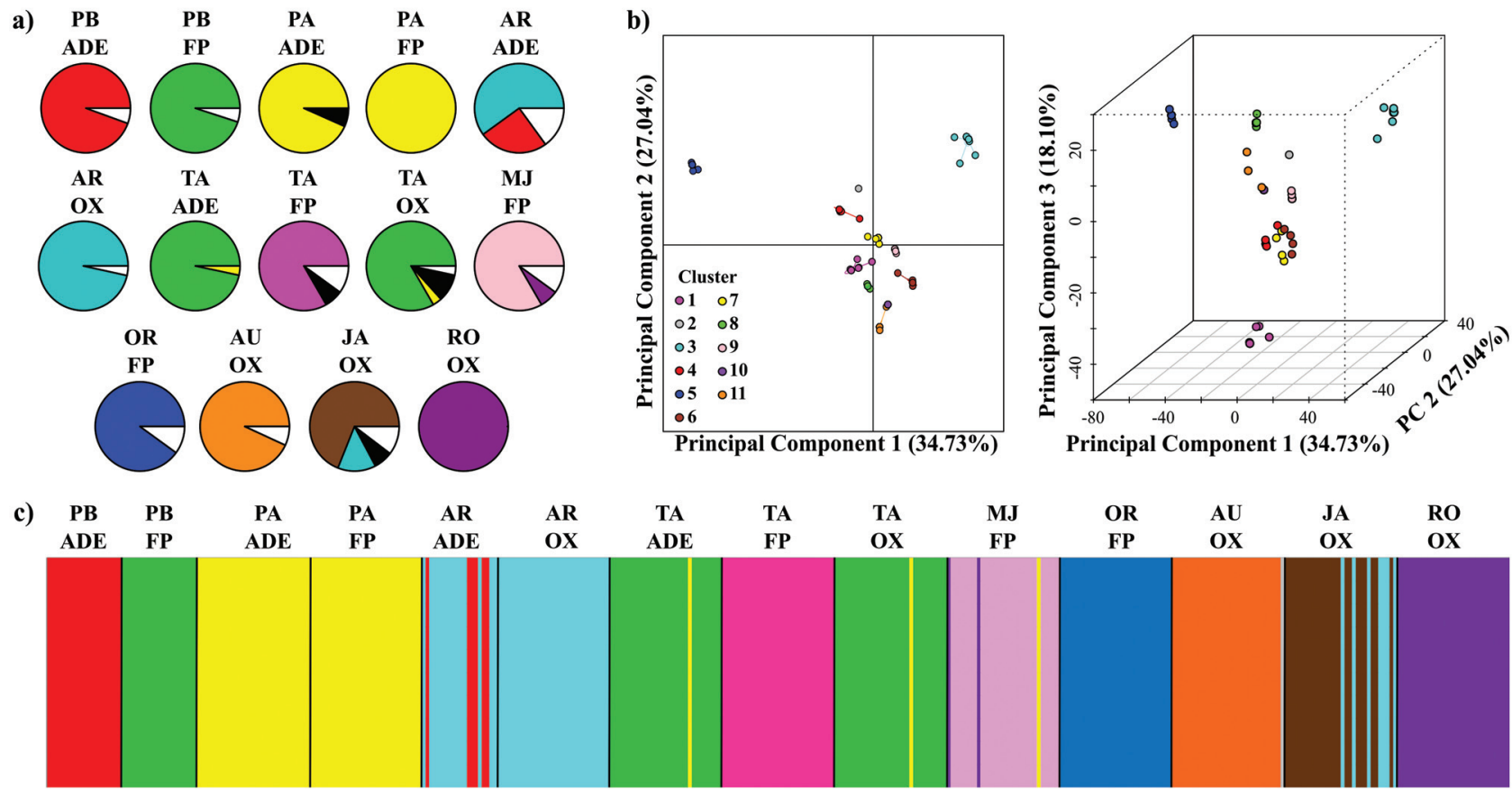

$\begin{array}{cccc}\text { TA } & \text { TA } & \text { TA } & \text { MJ } \\ \text { ADE } & \text { FP } & \text { OX } & \text { FP }\end{array}$

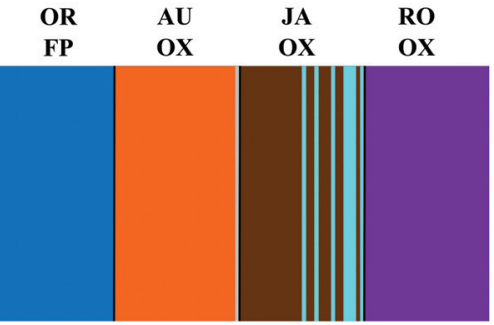

Figure 2 - Comparison of genetic diversity and structure of bitter manioc varieties cultivated in three soil types in Manicoré, Amazonas, Brazil. a) Proportions of multilocus genotypes (MLGs), where different colors represent distinct MLGs. Black sections represent individuals that shared MLGs different from the dominant MLGs of their varieties (those in different varieties correspond to distinct MLGs). White sections represent unique MLGs for the whole set of varieties (and each section may be composed of more than one MLG). b) 2-D and 3-D results of DAPC analysis at $K$-means $=11$ groups. c) Structure-like barplot based on individuals' membership probabilities to clusters generated in DAPC. Each individual is represented as a vertical line partitioned into colored segments, the length of which is the probability of the individual belonging to each $K$-means cluster. Figures were colored according to the preponderant MLG found in each variety. The identification of varieties follows the acronyms in Table 1.

on an Oxisol). The number of DAPC clusters matched neither the number of varieties (14) nor the number of different vernacular names (9). Generally, varieties with the same vernacular name were in the same cluster, except for Tartaruga from the floodplain, which was in a different cluster from Tartaruga found in ADE and Oxisols. These latter two varieties were grouped in the same cluster as the variety Pirarucu Branco from the floodplain. Thus, from the total of 10 genetic groups recovered in DAPC, seven of them contained only one variety, another two were formed with varieties that had equal names but grown in different soils [Pirarucu Amarelo (from the floodplain and ADE), Arroz (from ADE and Oxisol)], and one was formed by varieties with different vernacular names [Tartaruga (from ADE and Oxisols) plus Pirarucu Branco (from the floodplain)]. DAPC and the comparisons of MLGs among varieties clearly showed that the same MLGs were present in different varieties. The varieties that were assigned to the same DAPC cluster showed the same MLGs, and the other varieties, each one assigned to a distinct cluster, had distinct predominant MLGs. These DAPC results were exactly the same as the DAPC based on the a-score criterion, and also highly congruent with the results of the Bayesian model-based analysis carried out in TESS (Figure S1).

Measures of genetic differentiation estimated among the set of different MLGs present in each bitter manioc va- riety generally revealed very high values for pairwise $F_{S T}$ between different varieties (Table 3). Some varieties with equivalent vernacular names but grown in different soil types (Tartaruga on Oxisols and Tartaruga in the floodplain, for example) also presented high differentiation values.

When comparing the MLGs for each variety, the analysis of molecular variance (AMOVA) revealed that most genetic variation is found within varieties $(81.38 \%)$, but with a large proportion of variation $\left(\Phi_{S T}=\right.$ 0.186 , significant at $\mathrm{p}<0.001$ ) also found among them (Table 4). Additional AMOVAs showed that little variation was found among soil types and among communities.

Relationships among the varieties based on the genetic distance $\mathrm{D}_{\mathrm{A}}$ (Nei et al., 1983) using the NeighborJoining algorithm corroborated the interpretations of the DAPC results (Figure 3). Varieties that were grouped in the same DAPC cluster were also closer to each other in the dendrogram, and had high bootstrap support. Reasonable bootstrap support was also found between Jabuti and Arroz. Soil type did not influence grouping of varieties. 


\section{Discussion}

Maintenance and increase of genetic diversity within bitter manioc varieties

Considerable excess of heterozygotes was found for all bitter manioc varieties analyzed. Observed heterozygosities much higher than expected heterozygosities were also found in the manioc varieties cultivated by Palikur Amerindians in French Guiana studied by Pujol et al. (2005), because the Palikur frequently retain heterozygous volunteer seedlings in their swiddens. Pujol et al. (2005) and Pujol and McKey (2006) demonstrated that the size of seedlings was correlated with their multilocus heterozygosities and with their survival. During the weeding of swiddens, small seedlings are removed and larger ones are retained, and these more heterozygous seedlings become candidates for subsequent clonal propagation. Such a process allows the increase of genetic diversity (through incorporation of seedlings) and the maintenance of heterozygosity (through clonal propagation) in manioc varieties (Pujol et al., 2005).

The analysis of multilocus genotypes (MLGs) revealed that almost all bitter manioc varieties were polyclonal, with a preponderance of one clone and a mixture of other different genotypes, as observed by previous authors studying other manioc varieties in different parts of Amazonia (Elias et al., 2001; Peroni et al., 2007; Pujol et al., 2007). The incorporation of new MLGs in a given variety may occur by the incorporation of volunteer seedlings, and by unintentional admixture of plants from different varieties by farmers. Subsequent clonal propagation in the next cultivation cycle is responsible for the increase in the number of individuals with the new MLG within the variety. McKey et al. (2010b) comment on the contribution of somatic mutations to increase genetic diversity within clonally propagated crops. However, this is unlikely to explain the variation of MLGs found in this study, since the set of microsatellites used only covers a very small fraction of the estimated $772 \mathrm{Mb}$ manioc genome (Awoleye et al., 1994; International Cassava Genetic Map (ICGMC), 2014).

Interestingly, about one-third of the farmers from two communities along the middle Madeira River intentionally use volunteer seedlings for clonal propagation, selecting the more attractive or healthy plants, and cultivating them separately for later evaluation (Fraser and Clement, 2008). These authors also observed farmers who unintentionally incorporated seedlings into existing varieties, allowing them to grow and later propagating them clonally without discriminating them from the other individuals of the cultivated variety. Extending their previous findings, Fraser et al. (2012) report that the proportion of farmers in six communities along the middle Madeira River that intentionally or unintentionally incorporate seedlings varies from $11 \%$ $32 \%$ and from $9 \%-33 \%$ per community, respectively. 
Hence, the incorporation of seedlings followed by clonal propagation plays an important role in the increase of genetic diversity in varieties cultivated along the middle
Madeira River, just as occurs among the Makushi and Palikur Amerindians (Elias et al., 2001; Pujol et al., 2005, 2007).

Table 4 - Analysis of molecular variance for hierarchical groupings of 14 bitter manioc varieties grown in ADE, Oxisols and floodplain soils in communities in Manicoré, Amazonas, Brazil. The levels analyzed were: among the varieties; among varieties within soil types; among varieties within communities. d.f. $=$ degrees of freedom

\begin{tabular}{|c|c|c|c|c|}
\hline Source of variation & d.f. & Sum of squares & Components of variation & Percentage of variation \\
\hline Among varieties & 13 & 74.24 & 0.54 & 18.62 \\
\hline Within varieties & 74 & 175.41 & 2.37 & 81.38 \\
\hline Total & 87 & 249.65 & 2.91 & \\
\hline Among soil types & 2 & 15.61 & 0.05 & 1.84 \\
\hline Among varieties within soil types & 11 & 58.63 & 0.50 & 17.20 \\
\hline Within varieties & 74 & 175.41 & 2.37 & 80.97 \\
\hline Total & 87 & 249.65 & 2.92 & \\
\hline Among communities & 4 & 31.30 & 0.12 & 4.24 \\
\hline Among varieties within communities & 9 & 42.94 & 0.44 & 14.95 \\
\hline Within varieties & 74 & 175.41 & 2.37 & 80.81 \\
\hline
\end{tabular}

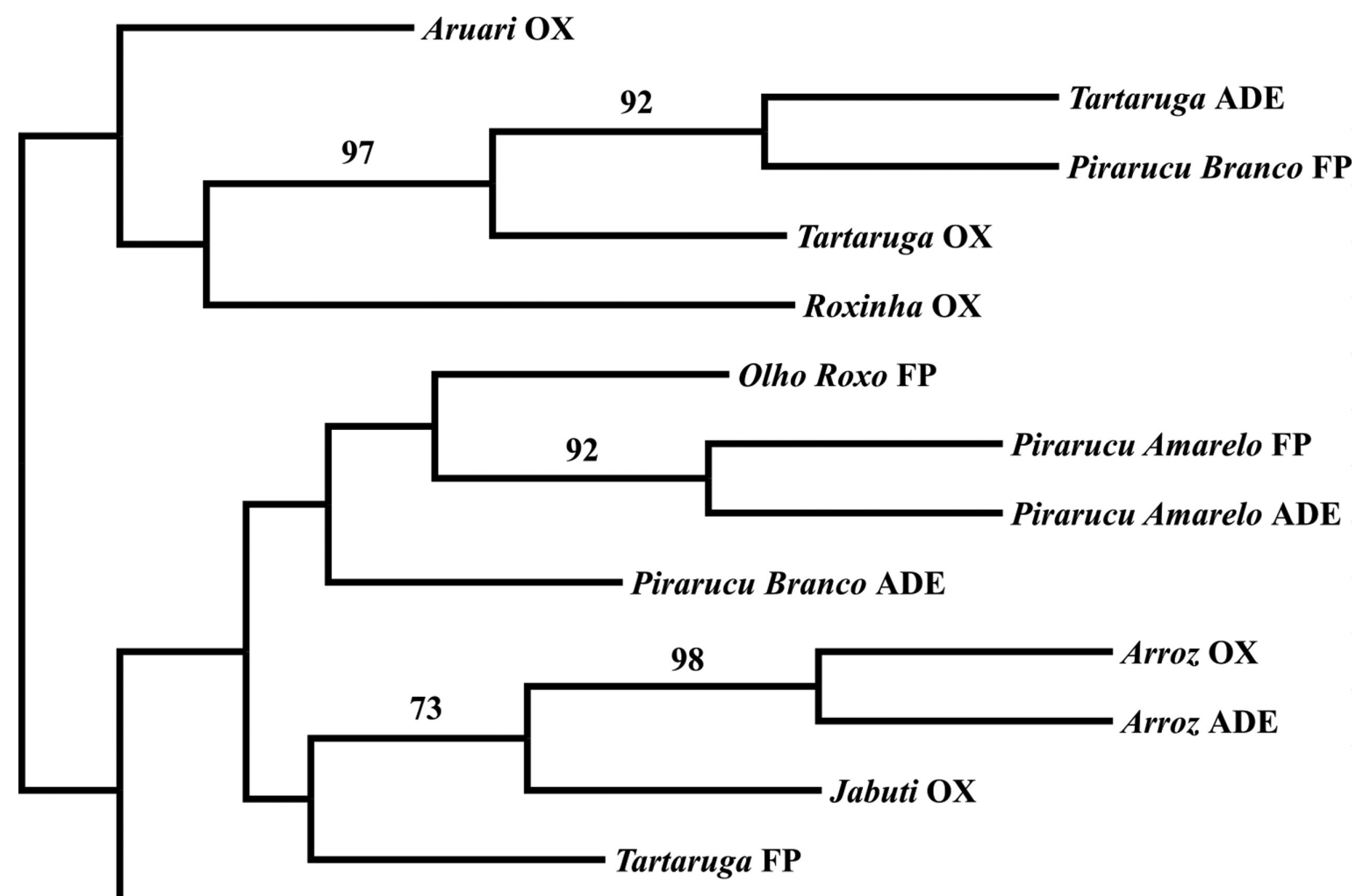

Mãe Joana FP

\subsection{5}

Figure 3 - Neighbor-Joining dendrogram based on the Nei et al. (1983) genetic distance $\left(\mathrm{D}_{\mathrm{A}}\right)$, showing the relationships among 14 varieties grown in different soil types in Manicoré, Amazonas, Brazil. Soil types are coded as ADE (Amazonian dark earths), FP (floodplain) and OX (Oxisols). Bootstrap values greater than $70 \%$ are indicated. 


\section{Genetic structure of bitter manioc varieties}

Since pairwise $F_{S T}$ s were estimated with only one individual per MLG found within each variety, their values must be interpreted with caution. In general, varieties had high values of pairwise $F_{S T}$ s, which shows that the set of MLGs present in each variety is highly differentiated from that in other varieties. Low values of $F_{S T}$ were found between varieties that were in different DAPC clusters and that were distantly related in the dendrogram, so these may be an artefact of the sample size reduction we used before calculating the estimates. However, it is clear that the set of MLGs in these varieties had substantially different allelic compositions (Figure 2a).

Fraser and Clement (2008) and Fraser (2010) observed similar agronomic traits in varieties from ADE and from the floodplain, and suggested that the varieties of these two soil types would be genetically closer and more divergent from the varieties grown in Oxisols. However, the individuals of Tartaruga and Pirarucu Branco from the floodplain did not cluster together with the individuals of the same variety from ADE (Figure 3). Additionally, the individuals of Tartaruga and Arroz from ADE were grouped with the individuals of corresponding varieties from Oxisols. There seems to be a tendency for varieties from the floodplain to be genetically differentiated from corresponding varieties in upland soils, e.g., Tartaruga. This may not be a general tendency, since individuals of Pirarucu Amarelo from the floodplain and ADE shared the same predominant MLG. Therefore, our results do not reflect the expectations of the hypothesis derived from ethnobotanical observations (Fraser and Clement, 2008; Fraser, 2010), because varieties from $\mathrm{ADE}$ and the floodplain were strongly differentiated, and because varieties clustered independently from soil types. The exception (Pirarucu Amarelo varieties from the floodplain and ADE) may be due to the fact that these were the only two varieties with the same vernacular name sampled in different soils of the same community. As observed by Fraser et al. (2012), the composition of bitter manioc varieties is clearly different on different types of soil in the middle Madeira River region, with higher differentiation between varieties from floodplain in relation to varieties from other types of soil. Genetic differentiation in bitter manioc varieties across soil types was also observed with molecular markers (Alves-Pereira et al., 2011). Farmers' convergent selection for similar ecological adaptations to nutrient-rich soils may be the reason why $\mathrm{ADE}$ and floodplain varieties share agronomic characteristics (Fraser et al., 2012), rather than shared phylogeny. Fast maturing and low starch varieties may be the outcomes of selection for rapid growth required in more intensive cultivation systems generally found in floodplain and ADE soils, as well as different soil conditions that may cause differences in stress to plants (Fraser et al., 2012). Among these stress conditions, the differences in annual flood regimes among different zones within the floodplain may influence the selection of an increasing number of varieties that may be suitable for cultivation there. This, in turn, may contribute to increasing genetic diversity within floodplain varieties, as well as increasing genetic differentiation of these varieties in relation to the varieties grown in other soil types. Therefore, the convergent selection proposed by Fraser et al. (2012) may be contributing to the maintenance and amplification of genetic diversity among bitter manioc varieties cultivated along the middle Madeira River.

The genetic structure revealed by DAPC and Bayesian analysis using TESS was corroborated by the relationships among varieties shown by the Neighbor-Joining dendrogram. The lack of bootstrap support for most of the branches may be due to the fact that, as shown by values of $F_{S T}$ and detected by clustering in DAPC and TESS, the varieties sampled are so distinct from each other that it may be difficult to establish genetic relationships among them without many more microsatellite loci. The reasonable support found for the relationship between Arroz and Jabuti, also detected by DAPC and TESS, may be explained by the large number of MLGs shared by these two varieties. On the other hand, the clustering produced by DAPC and TESS showed that several individuals of Arroz from ADE were clustered with individuals of Pirarucu Branco from ADE, although they were not closely related in the Neighborjoining dendrogram (Figure 3). This may be due to the higher similarity in allele frequencies, or even in allele composition, between the varieties Arroz and Jabuti, as suggested by the lower $F_{S T}$ found between Arroz (ADE)/Jabuti (Oxisol) than between Arroz (ADE)/Pirarucu Branco (Floodplain) (-0.029 and 0.229, respectively), and by the composition of MLGs in these varieties.

The high levels of heterozygosity certainly reflected the high proportion of genetic variation within varieties revealed by AMOVA. On the other hand, the low genetic variation among manioc varieties in different soils and among communities was rather surprising since the floodplain communities had a generally different set of varieties when compared to the upland communities (ADE and Oxisols) (Alves-Pereira et al., 2011; Fraser et al., 2012). The fact that varieties with the same vernacular names, but sampled in different soils of different communities, were in general grouped in the same cluster of DAPC and TESS, reinforces the finding that the greatest genetic divergence is found among the varieties cultivated in the middle Madeira River, rather than among soils, and AMOVA results are in accordance.

DAPC cluster number 2 was represented by a single individual of the Aruari variety from an Oxisol. This individual presented one of the two unique MLGs found in Aruari. Given the general genetic distinction among varieties, it is possible that this individual belongs to another variety that has phenotypic similarities with Aruari, which might have caused the farmer to incorporate it in Aruari. It is also possible that this individual originated from sexual reproduction among varieties. Another intriguing result was that the variety Pirarucu Branco from the floodplain 
was shown to be almost identical to the variety Tartaruga from ADE and Oxisol. These varieties had the same predominant MLG, even though Pirarucu Branco was collected in a community different from the others. It is possible that the set of microsatellite loci were not sufficient for finding allelic differences between these varieties. Additionally, it is possible that genotype $\mathrm{x}$ environment (GxE) interactions may have an important role in explaining this finding, since phenotypic plasticity may be present among the traits that were most favored by selection during crop domestication (McKey et al., 2012). Boster (1985) discusses the "selection for perceptual distinctiveness", in which selection is performed by farmers in order to recognize their varieties as a group of individuals that share a specific set of morphological characteristics that are different from other varieties. Therefore, it is possible that when the variety Tartaruga was moved from the uplands (ADE or Oxixols) to the floodplain (or vice versa) it underwent a name change due to differential phenotypic expression of the same genotype in different environments. There also may be a certain range of variation in the morphological characteristics that identify each variety (Boster, 1985; Elias et al., 2000; Duputié et al., 2009). In spite of having distinct MLGs, different individuals may present a set of morphological characteristics that are sufficiently similar to be grouped into the same range of phenotypic variation, which encourages farmers to give them the same varietal name. This is a possible explanation for the fact that the individuals of Pirarucu Branco from floodplain were genetically differentiated from those of ADE, and the same explanation may hold for the individuals of Tartaruga from floodplain, which were genetically distinct from the individuals of upland soils (ADE and Oxisol). GxE interactions were already documented for cyanogenic potential and nutrient composition in manioc (Bokanga et al., 1994; Burns et al., 2012), so it is not surprising to find other traits that may be due to GxE interactions. Studies on the variation of morphological characteristics among varieties of manioc grown along the middle Madeira river may be valuable to cast light on the occurrence of GxE interactions, and also on the genetic evidence found in our study.

Individuals that were clustered by DAPC and TESS separately from the rest of the individuals of a given variety displayed MLGs identical to predominant MLGs of a different variety (for example, between Arroz and Pirarucu Branco from ADE). These results may be due to farmers' confusion when assigning individuals to varieties. However, the term 'confusion' is relative because GxE interactions may influence the naming of varieties (Emperaire et al., 1998), and because the criteria for distinguishing varieties may vary among farmers (Salick et al., 1997; Sambatti et al., 2001; Emperaire and Peroni, 2007; Heckler and Zent, 2008).

Indeed, all the factors discussed here may be shaping the extent of genetic diversity and structure among bitter manioc varieties in the region of the middle Madeira River.
These include, for example, the exchange of material among farmers, rates of incorporation of seedlings, and the naming of varieties may vary greatly among and even within different regions (Sambatti et al., 2001; Peroni and Hanazaki, 2002; Fraser and Clement, 2008; Oliveira, 2008). However, whatever the most important processes for the results reported in this study, they ultimately contribute to the maintenance of high genetic diversity within the varieties traditionally cultivated in communities of smallholder farmers along the middle Madeira River.

This study was the first to report on the genetic diversity and the genetic structure of bitter manioc varieties traditionally grown in different soil types in a small geographic region. Microsatellite variation revealed that traditional farmers of different communities along the middle Madeira River manage high levels of genetic diversity within some of the most frequently cultivated varieties in the region. Although there is large intra-varietal genetic diversity, varieties have distinct genetic features that, in general, differentiate one from the other. The genetic structure is primarily related to the varieties per se, and there was no clear tendency to greater similarity between varieties from the floodplain and ADE. Rather, there seems to be a differentiation between varieties grown in the floodplain and the same varieties grown in upland soils (ADE and Oxisols), so the hypothesis proposed by Fraser and Clement (2008) and Fraser (2010) is not supported by our study. It is more likely that farmers in the middle Madeira River region select their $\mathrm{ADE}$ and floodplain varieties for convergent adaptive traits (fast maturing, low starch), which are possibly associated with the similar ecological adaptations to fertile soils and short periods of growth (Fraser et al., 2012). The genetic differentiation of some of the floodplain varieties in relation to upland $\mathrm{ADE}$ and Oxisol varieties may be due to the selection of a distinct set of varieties for different flood regimes in different zones within floodplain soils. These may be a signature of physiological adaptations to flood regimes or edaphic properties, for example. The evaluation of morphometric characters in bitter manioc varieties grown in different soil types in the middle Madeira may be useful to better understand the possible existence of convergent adaptations.

Our study suggests that many factors may contribute to the maintenance and amplification of genetic diversity within bitter manioc varieties cultivated in communities along the middle Madeira River. We believe that it is worthwhile to invest in social policies that value the practices of smallholders, as they manage high levels of genetic diversity within their cultivated varieties of bitter manioc. These farmers must be seen as collaborators for the on-farm in-situ conservation of the genetic resources of manioc.

\section{Acknowledgments}

This work was financially supported by the Conselho Nacional de Desenvolvimento Científico e Tecnológico - 
CNPq/Brazil (CT Amazônia grant. no. 575588/08-0, led by $\mathrm{CRC}$ ), supported by the Programa de Pós Graduação em Genética, Conservação e Biologia Evolutiva (PPGGCBEv/INPA), and was part of AAP's Master's thesis. We thank all traditional farmers in the riverside communities of Manicoré who shared their time and allowed sample collections. We thank André Braga Junqueira, Doriane Picanço Rodrigues, Michelly de Cristo-Araújo for field and laboratory help. We thank Doyle McKey for comments on the manuscript. AAP thanks the Coordenação de Aperfeiçoamento de Pessoal de Nível Superior - CAPES for a Masters scholarship. CRC, MIZ and MRL are recipients of CNPq research fellowships.

\section{References}

Allem AC (1994) The origin of Manihot esculenta Crantz (Euphorbiaceae). Genet Resour Crop Evol 41:133-150.

Alves-Pereira A, Peroni N, Abreu AG, Gribel R and Clement CR (2011) Genetic structure of traditional varieties of bitter manioc in three soils in Central Amazonia. Genetica 139:1259-1271.

Arnaud-Haond S and Belkhir K (2007) GENCLONE: A computer program to analyse genotypic data, test for clonality and describe spatial clonal organization. Mol Ecol Notes 7:15-17.

Awoleye F, van Duren M, Dolezel J and Novak FJ (1994) Nuclear DNA content and in vitro induced somatic polyploidization cassava (Manihot esculenta Crantz) breeding. Euphytica 76:195-202.

Bokanga M, Ekanayake IJ, Dixon AGO and Porto MCM (1994) Genotype-environment interactions for cyanogenic potential in cassava. Acta Hortic 375:131-139.

Boster JS (1985) Selection for perceptual distinctiveness: Evidence from Aguaruna cultivar of Manihot esculenta. Econ Bot 39:310-325.

Bradbury EJ, Duputié A, Delêtre M, Roullier C, Trujillo AN, Manu-Aduening JW, Emshwiller E and McKey D (2013) Geographic differences in patterns of genetic differentiation among bitter and sweet cassava (Manihot esculenta: Euphorbiaceae). Am J Bot 100:857-866.

Burns AE, Gleadow RM, Zacarias AM, Cuambe CE, Miller RE and Cavagnaro TR (2012) Variations in the chemical composition of cassava (Manihot esculenta Crantz) leaves and roots as affected by genotypic and environmental Variation. J Agri Food Chem 60:4946-56.

Chavarriaga-Aguirre P, Maya MM, Bonierbale MV, Kreolich S, Fregene MA, Toehne J and Kochert G (1998) Microsatellites in cassava (Manihot esculenta Crantz): Discovery, inheritance and variability. Theor Appl Genet 97:493-501.

Chen C, Durand E, Forbes F and François O (2007) Bayesian clustering algorithms ascertaining spatial population structure: A new computer program and a comparison study. Mol Ecol Notes 7:747-756.

Dieringer D and Schlötterer C (2003) Microsatellite analyzer (MSA): A platform independent analysis tool for large microsatellite data sets. Mol Ecol Notes 3:167-169.

Doyle JJ and Doyle JL (1987) Isolation of plant DNA from fresh tissue. Focus 1:13-15.

Duputié A, Massol F, David P, Haxaire C and McKey D (2009) Traditional Amerindian cultivators combine directional and ideotypic selection for sustainable management of cassava genetic diversity. J Evol Biol 22:1317-1325.
Durand E, Jay F, Gaggiotti OE and François O (2009) Spatial inference of admixture proportions and secondary contact zones. Mol Biol Evol 26:1963-1973.

Elias M, Rival L and McKey D (2000) Perception and management of cassava (Manihot esculenta Crantz) diversity among Makushi Amerindians of Guyana (South America). J Ethnobiol 20:239-265.

Elias M, Penet L, Vindry P, McKey D, Panaud O and Robert T (2001) Unmanaged sexual reproduction and the dynamics of genetic diversity of a vegetatively propagated crop plant, cassava (Manihot esculenta Crantz), in a traditional farming system. Mol Ecol 10:1895-1907.

Emperaire L (2005) L'agrobiodiversité en Amazonie brésilienne: Ressource et patrimoine. J d'Ethnobiol 42:413-426.

Emperaire L and Peroni N (2007) Traditional management of agrobiodiversity in Brazil: A case study of manioc. Hum Ecol 35:761-768.

Emperaire L, Pinton F and Second G (1998) Gestion dynamique de la diversité varie tale du manioc en Amazonie du nordouest. Natures Sci Societes 6:27-42.

Evanno G, Regnaut S and Goudet J (2005) Detecting the number of clusters of individuals using the software STRUCTURE: A simulation study. Mol Ecol 14:2611-2620.

Excoffier L and Lischer HEL (2010) Arlequin suite ver 3.5: A new series of programs to perform population genetics analyses under Linux and Windows. Mol Ecol Resour 10:564567.

Fraser JA (2010) The diversity of bitter manioc (Manihot esculenta Crantz) cultivation in a whitewater Amazonian landscape. Diversity 2:586-609.

Fraser JA and Clement CR (2008) Dark Earths and manioc cultivation in Central Amazonia: A window on pre-Columbian agricultural systems? Bol Mus Paraense Emilio Goeldi Ciênc Hum 3:175-194.

Fraser JA, Alves-Pereira A, Junqueira AB, Peroni N and Clement CR (2012) Convergent adaptations: Bitter manioc cultivation systems in fertile anthropogenic dark earths and floodplain soils in central Amazonia. PLoS ONE 7:e43636.

Glaser B and Birk JJ (2012) State of the scientific knowledge on properties and genesis of Anthropogenic Dark Earths in Central Amazon (terra preta de Indio). Geochim Cosmochim Acta 82:39-51.

Gutjahr E (2000) Prospects for arable farming in the floodplains of the Central Amazon. In: Junk WJ, Ohly JJ, Piedade MTF and Soares MGM (eds) The Central Amazon Floodplain: Actual Use and Options for a Sustainable Management. Backhuys, Leiden, pp 141-170.

Heckler S and Zent S (2008) Piaroa manioc varietal: Hyperdiversity or social currency? Hum Ecol 36:679-697.

International Cassava Genetic Map Consortium (ICGMC) (2014) High-resolution linkage map and chromosome-scale genome assembly for cassava (Manihot esculenta Crantz) from 10 populations. G3 (Bethesda) 5:133-144.

Jombart T and Ahmed I (2011) Adegenet 1.3-1: New tools for the analysis of genome-wide SNP data. Bioinformatics 27:3070-3071.

Jombart T, Devillar S and Balloux F (2010) Discriminant analysis of principal components: A new method for the analysis of genetically structured populations. BMC Genet 11:94.

Lebot V (2009) Tropical Root and Tuber Crops: Cassava, Sweet Potato, Yams and Aroids. CAB International, Oxford, $413 \mathrm{p}$.

Mba REC, Stephenson P, Edwards K, Mlezer S, Mkumbira J, Gullberg U, Apel K, Gale M, Tohme J and Fregene M 
(2001) Simple sequence repeat (SSR) markers survey of the cassava (Manihot esculenta Crantz) genome: Towards an SSR-based molecular genetic map of cassava. Theor Appl Genet 102:21-31.

McKey D and Beckerman S (1993) Chemical ecology, plant evolution and traditional Manioc cultivation systems. In: Hladik CM, Linares OF, Pagezy H, Semple A and Hadley M (eds) Tropical Forests, People and Food Biocultural Interactions and Applications to Development. Vol. 13. Parthenon Carnforth and UNESCO, Paris, pp 83-112.

McKey D, Cavagnaro TR, Cliff J and Gleadow R (2010a) Chemical ecology in coupled human and natural systems: People, manioc, multitrophic interactions and global change. Chemoecology 20:109-133.

McKey D, Elias M, Pujol B and Duputié A (2010b) The evolutionary ecology of clonally propagated domesticated plants. New Phytol 186:318-332.

McKey D, Elias M, Pujol B and Duputié A (2012) Ecological approaches to plant domestication. In: Gepts P, Famula T, Bettinger R, Brush SB, Damania AB, McGuire PE and Qualset CO (eds) Biodiversity in Agriculture: Domestication, Evolution and Sustainability. Cambridge University Press, Cambridge, pp 377-406.

Mühlen GS, Martins OS and Ando A (2000) Variabilidade genética de etnovariedades de mandioca, avaliada por marcadores de DNA. Sci Agr 57:319-328.

Mühlen GS, Alves-Pereira A, Clement CR and Valle TL (2013) Genetic diversity and differentiation of Brazilian bitter and sweet manioc varieties (Manihot esculenta Crantz, Euphorbiaceae) based on SSR molecular markers. Tipití 11:66-73.

Nei M, Tajima F and Tateno Y (1983) Accuracy of estimated phylogenetic trees from molecular data. J Mol Evol 19:153170 .

Oliveira JC (2008) Social networks and cultivated plants. Tipití 6:101-110.

Olsen KM and Schaal BA (1999) Evidence on the origin of cassava: Phylogeography of Manihot esculenta. Proc Natl Acad Sci U S A 96:5586-5591.

Peakall R and Smouse PE (2012) GenAlEx 6.5: Genetic analysis in Excel. Population genetic software for teaching and research - An update. Bioinformatics 28:2537-2539.

Peroni N and Hanazaki N (2002) Current and lost diversity of cultivated varieties, especially cassava, under swidden cultivation systems in the Brazilian Atlantic Forest. Agr Ecosyst Environ 92:171-183.

Peroni N, Kageyama PY and Begossi A (2007) Molecular differentiation, diversity, and folk classification of "sweet" and "bitter" cassava (Manihot esculenta) in Caiçara and Caboclo management systems (Brazil). Genet Resour Crop Evol 54:1333-1349.

Pritchard JK, Stephens M and Donnelly P (2000) Inference of population structure using multilocus genotype data. Genetics 155:945-959.

Pujol B and McKey D (2006) Size asymmetry in intraspecific competition and the density-dependence of inbreeding depression in a natural plant population: A case study in cas- sava (Manihot esculenta Crantz, Euphorbiaceae). J Evol Biol 19:85-96.

Pujol B, David P and McKey D (2005) Microevolution in agricultural environments: How a traditional Amerindian farming practice favours heterozygosity in cassava (Manihot esculenta Crantz, Euphorbiaceae). Ecol Lett 8:138-147.

Pujol B, Renoux F, Elias M, Rival L and McKey D (2007) The unappreciated ecology of landrace populations: Conservation consequences of soil seedbanks in cassava. Biol Conserv 136:541-551.

Rival L and McKey D (2008) Domestication and diversity in manioc (Manihot esculenta Crantz ssp. esculenta, Euphorbiaceae). Curr Anthropol 49:1119-1128.

Saitou N and Nei M (1987) The neighbor-joining method: A new method for reconstructing phylogenetic trees. Mol Biol Evol 4:406-425.

Salick J, Cellinese N and Knapp N (1997) Indigenous diversity of cassava: Generation, maintenance, use and loss among the Amuesha, Peruvian Upper Amazon. Econ Bot 51:6-19.

Sambatti JBM, Martins PS and Ando A (2001) Folk taxonomy and evolutionary dynamics of cassava: A case study in Ubatuba, Brazil. Econ Bot 55:93-105.

\section{Internet Resources}

Belkhir K, Borsa P, Chikhi L, Raufaste N and Bonhomme F (2002) GENETIX 4.03, Logiciel Sous Windows Pour la Génétique Des Populations. Laboratoire Génome, Populations, Interactions, Université Montpellier II, Montpellier, France, http://kimura.univ-montp2.fr/genetix/ (January 15, 2013).

Felsenstein J (2005) PHYLIP (Phylogeny Inference Package), version 3.6. Computer program distributed by the author, Department of Genome Sciences, University of Washington, Seattle, http://www.phylip.com/ (January 15, 2013).

FigTree software, http://ree.bio.ed.ac.uk/software/figtree/ (January 15,2013$)$.

\section{Supplementary Material}

The following material is available for this article:

- Table S1 - Table of private alleles (with frequencies $>$ 0.05 ) found in bitter manioc varieties in different soil types in Manicoré, Amazonas, Brazil.

- Table S2 - List of multilocus genotypes (MLGs) across bitter manioc varieties in different soil types in Manicoré, Amazonas, Brazil.

- Figure S1 - Criteria for choosing the optimal number of clusters $(K)$ for TESS and DAPC, and comparison of individuals' assignments obtained with DAPC optimized with a-score and TESS.

\section{Associate Editor: Dario Grattapaglia}

License information: This is an open-access article distributed under the terms of the Creative Commons Attribution License (type CC-BY), which permits unrestricted use, distribution and reproduction in any medium, provided the original article is properly cited. 